\title{
Electrophysiological Properties of AMPA Receptors Are Differentially Modulated Depending on the Associated Member of the TARP Family
}

\author{
Sabine Kott, Markus Werner, Christoph Körber, and Michael Hollmann \\ Department of Biochemistry I, Receptor Biochemistry, Ruhr University Bochum, D-44780 Bochum, Germany
}

\begin{abstract}
The family of AMPA receptors is encoded by four genes that are differentially spliced to result in the flip or flop versions of the four subunits GluR1 to GluR4. GluR2 is further modified at the so-called Q/R site by posttranscriptional RNA editing. Delivery of AMPA receptors to the plasma membrane and synaptic trafficking are controlled by transmembrane AMPA receptor regulatory proteins (TARPs). Additionally, TARPs influence essential electrophysiological properties of AMPA receptor channels such as desensitization and agonist efficacies. Here, we compare the influence of all known TARPs $(\gamma 2, \gamma 3, \gamma 4$, and $\gamma 8)$ on agonist-induced currents of the four AMPA receptor subunits, including flip and flop splice variants and editing variants. We show that, although agonist-induced currents of all homomeric AMPA receptor subunits as well as all heteromeric combinations tested are significantly potentiated when coexpressed with members of the TARP family in Xenopus laevis oocytes, the extent of TARP-mediated increase in agonist-induced responses is highly dependent on both the AMPA receptor subunit and the coexpressed TARP. Moreover, we demonstrate that the splice variant of the AMPA receptor plays a key role in determining the modulation of electrophysiological properties by associated TARPs. We furthermore present evidence that individual TARP-AMPA receptor interactions control the degree of desensitization of AMPA receptors. Consequently, because of their subunit-specific impact on the electrophysiological properties, TARPs play a major role as modulatory subunits of AMPA receptors and thus contribute to the functional diversity of AMPA receptors encountered in the CNS.
\end{abstract}

Key words: glutamate receptor; stargazin; TARP; trafficking; voltage clamp; AMPA receptor

\section{Introduction}

AMPA receptors mediate most of the fast excitatory synaptic transmission in the vertebrate CNS and play an essential role in plasticity of excitatory synapses. The AMPA receptor family consists of four subunits GluR1 to GluR4 (Hollmann and Heinemann, 1994) forming functional homotetrameric and heterotetrameric receptor complexes (Rosenmund et al., 1998; Hollmann, 1999). Subunit diversity is increased by alternative splicing, leading to two splice variants for each AMPA receptor, named flip and flop (Sommer et al., 1990). Subunit heterogeneity is further increased by posttranscriptional RNA editing at the so-called Q/R site that determines electrophysiological properties and surface expression of the receptor complexes (Hollmann et al., 1991; Hume et al., 1991; Swanson et al., 1997; Greger et al., 2002, 2003).

In contrast to NMDA receptors, synaptic AMPA receptors undergo fast turnover (Sheng and Lee, 2003; Collingridge et al., 2004; Cognet et al., 2006). Stargazin ( $\gamma 2)$ and three homologous

Received Sept. 25, 2006; revised Feb. 27, 2007; accepted Feb. 28, 2007.

We thank Petra Wahle (Department of General Zoology and Neurobiology, Developmental Neurobiology Group, Ruhr University Bochum) for providing rat brain tissue. We also thank Daniel Tapken for critical reading of this manuscript and Björn Peters for expert oocyte preparations.

Correspondence should be addressed to Dr. Michael Hollmann, Department of Biochemistry I, Receptor Biochemistry, Building NC, Room 6/171, Ruhr University Bochum, Universitätsstraße 150, D-44780 Bochum, Germany. E-mail: michael.hollmann@rub.de.

DOl:10.1523/JNEUROSCI.4185-06.2007

Copyright $\odot 2007$ Society for Neuroscience $\quad$ 0270-6474/07/273780-10\$15.00/0 transmembrane AMPA receptor regulatory proteins (TARPs) $(\gamma 3, \gamma 4$, and $\gamma 8)$ appear to control AMPA receptor trafficking (Tomita et al., 2003; Nicoll et al., 2006). Studies indicate that in vivo the majority of AMPA receptors is associated with some TARP (Nakagawa et al., 2005; Vandenberghe et al., 2005). This association initiates two independent events: an increase in AMPA receptor surface expression (Chen et al., 2000) and a modulation of their electrophysiological properties. The observed enlargement of agonist-evoked currents can be attributable to a decrease in the extent of receptor desensitization, to an increase in the relative efficacy of kainate (KA), and to a slowed rate of receptor desensitization and deactivation (Priel et al., 2005; Tomita et al., 2005; Turetsky et al., 2005). $\mathrm{EC}_{50}$ values for glutamate and kainate shift toward lower concentrations in the presence of $\gamma 2$ (Yamazaki et al., 2004; Turetsky et al., 2005). Additionally, it has been shown for GluR4 that coexpression of $\gamma 2$ enlarges burst length and increases the probability of the channel to reach the highest conductance level (Tomita et al., 2005).

Up to now, modulatory effects of TARPs have almost exclusively been studied for $\gamma 2$, whereas effects of other TARPs have not been described in detail. In this study, we investigate the influence of all known TARPs on agonist-induced currents of all AMPA receptors, including their flip/flop splice variants and editing forms, in Xenopus laevis oocytes. Although TARPs consistently increase current amplitudes, potentiation factors vary widely and depend strongly on the particular receptor-TARP 
combination. Coexpression of TARPs also causes an increase in the ratio of kainate- to glutamate-induced currents, a modulation strongly dependent on both the AMPA receptor and the associated TARP. We demonstrate that the extent of this increase is primarily a result of TARP-specific modulation of desensitization. We propose that the modulation of the extent of receptor desensitization is a major functional consequence of TARP association. Furthermore, we show that each TARP shifts the effective glutamate concentration to a different extent. In summary, these data suggest that electrophysiological properties of AMPA receptors are modulated by all four TARPs in a receptor subunit- and TARP-specific manner.

\section{Materials and Methods}

Cloning of rat calcium channel $\gamma$ subunits. cDNAs encoding the rat calcium channel $\gamma$ subunits ( $\gamma 2$ is stargazin, $\gamma 3, \gamma 4$, and $\gamma 8$ ) were cloned by reverse transcription-PCR. First-strand cDNA was synthesized from rat brain total RNA using a First-Strand cDNA Synthesis kit (Fermentas, St. Leon-Rot, Germany) or SuperScriptIII reverse transcriptase (Invitrogen, Karlsruhe, Germany). Oligonucleotide PCR primers were designed based on published rat $\gamma$ subunit sequences (GenBank accession numbers AF361339 for $\gamma 2$, AF361340 for $\gamma 3$, AF361341 for $\gamma 4$, and AF361346 for $\gamma 8$ ) (Chu et al., 2001). The primers were tailed with either BamHI or $\mathrm{XbaI}$ restriction sites at the $5^{\prime}$ end and an EcoRI restriction site at the $3^{\prime}$ end to allow directed cloning into PSGEM, an expression vector for Xenopus oocytes (Villmann et al., 1997). To ensure full activity of the restriction sites, the palindromic sequences were capped by a random sequence of six nucleotides: $\gamma 2$ sense, $5^{\prime}$-ATAGCGGGATCCATTATGGGGCTGTTTGATCGAGGT-3'; $\gamma 2$ antisense, 5' -CGGCCGGAATTCTCATACGGGCGTGGTCCGGCGGTT- ${ }^{\prime} ; \gamma 3$ sense, $5^{\prime}$-GGCGGCGGATCCATTATGAGGATGTGTGACAGAGGTAT- $3^{\prime} ; \gamma 3$ antisense, $5^{\prime}$-CATCAGGAATTCTCAGACGGGCGTGGTGCG-3'; $\gamma 4$ sense, $5^{\prime}$-CGCGACGGATCCACCATGGTGCGATGCGACCGC-3'; $\gamma 4$ antisense, $5^{\prime}$-GGGCATGAATTCTCACACAGGGGTCGTCCGT-3'; $\gamma 8$ sense, 5' $^{\prime}$-TTCGAGTCTAGAAAACTGGAGTCATTGAAACGCTGGA-3'; and $\gamma 8$ antisense, $5^{\prime}$ GGGCGCGAATTCCTACACGGGCGTGGTTTTCCT-3'. After successful PCR, full-length cDNAs were cloned into PSGEM and verified by sequencing.

cRNA synthesis. cRNA synthesis was performed as described previously (Villmann et al., 1999). Briefly, template DNA was linearized with a suitable restriction enzyme. cRNA was synthesized from $1 \mu \mathrm{g}$ of linearized DNA using an in vitro transcription kit (Fermentas) with a modified protocol that uses $400 \mu \mathrm{M}$ GpppG (GE Healthcare, Freiburg, Germany) for capping and an extended reaction time of $3 \mathrm{~h}$ with T7 polymerase. Trace labeling was performed with $\left[\alpha-{ }^{32} \mathrm{P}\right] \mathrm{UTP}$ to allow calculation of yields and evaluation of transcript quality by formaldehyde agarose gel electrophoresis.

Electrophysiological measurements in Xenopus laevis oocytes. Frog oocytes of stages $\mathrm{V}$ or VI were surgically removed from the ovaries of $\mathrm{Xe}$ nopus laevis (Nasco, Fort Atkinson, WI) anesthetized with 3-aminobenzoic acid ethylester (1.5 g/L; Sigma-Aldrich, Taufkirchen, Germany). Lumps of $\sim 20$ oocytes were incubated for $1.5 \mathrm{~h}$ with 784 $\mathrm{U} / \mathrm{ml}(4 \mathrm{mg} / \mathrm{ml})$ collagenase type I (Worthington, Lakewood, NJ) in $\mathrm{Ca}^{2+}$-free Barth's solution (in mM: $88 \mathrm{NaCl}, 1.1 \mathrm{KCl}, 2.4 \mathrm{NaHCO}_{3}, 0.8$ $\mathrm{MgSO}_{4}$, and 15 HEPES-NaOH, pH 7.6) with slow agitation to remove the follicular cell layer and then washed extensively with Barth's solution [in mм: $88 \mathrm{NaCl}, 1.1 \mathrm{KCl}, 2.4 \mathrm{NaHCO}_{3}, 0.3 \mathrm{Ca}\left(\mathrm{NO}_{3}\right)_{2}, 0.4 \mathrm{CaCl}_{2}, 0.8$ $\mathrm{MgSO}_{4}$, and 15 HEPES-NaOH, pH 7.6]. Oocytes were maintained in Barth's solution supplemented with $100 \mu \mathrm{g} / \mathrm{ml}$ gentamicin, $40 \mu \mathrm{g} / \mathrm{ml}$ streptomycin, and $63 \mu \mathrm{g} / \mathrm{ml}$ penicillin. Defolliculated oocytes were injected with 2 ng of cRNA when receptor subunits were expressed alone and with $2.2 \mathrm{ng}$ for coexpression experiments with TARPs (2 $\mathrm{ng}$ of AMPAR-cRNA and $0.2 \mathrm{ng}$ of TARP-cRNA) using a nanoliter injector (World Precision Instruments, Sarasota, FL). In case of expression of heteromeric AMPA receptors, both cRNAs were mixed before injection and $2 \mathrm{ng}$ of the mixture were injected per oocyte. Four to $5 \mathrm{~d}$ after injection, oocyte current responses were recorded in magnesium frog Ringer's solution (MgR) (in mM: $115 \mathrm{NaCl}, 2.5 \mathrm{KCl}, 1.8 \mathrm{MgCl}_{2}$, and 10 HEPES- $\mathrm{NaOH}, \mathrm{pH}$ 7.2) under voltage clamp at $-70 \mathrm{mV}$ holding poten- tial with a TurboTec 10CX amplifier (npi Electronic, Tamm, Germany) controlled by Pulse software (HEKA Elektronik, Lambrecht, Germany). Recording pipettes were pulled from borosilicate glass (Hilgenberg, Malsfeld, Germany) using a PIP5 pipette vertical puller (HEKA Elektronik). Voltage electrodes had resistances of 1-4 $\mathrm{M} \Omega$ and were filled with $3 \mathrm{M} \mathrm{KCl}$; current electrodes had resistances of $0.5-1.5 \mathrm{M} \Omega$ and were filled with $3 \mathrm{M} \mathrm{CsCl}$. Compounds were applied for $20 \mathrm{~s}$ by superfusion at a flow rate of $\sim 5 \mathrm{ml} / \mathrm{min}$. Glutamatergic agonists (300 $\mu \mathrm{M}$ for Glu and $150 \mu \mathrm{M}$ for KA) were prepared in MgR. To determine $\mathrm{EC}_{50}$ values for glutamate, 10-12 different agonist concentrations were applied to the same oocyte, and steady-state values of the evoked currents were measured. Data from each oocyte were fitted separately, and $\mathrm{EC}_{50}$ values obtained this way from four to six oocytes were averaged. Data presented here are reported as mean $\pm S E M$. Statistical significance was determined with an unpaired Student's $t$ test.

Labeling of cell surface proteins using biotinylated concanavalin A. To identify the fraction of receptor protein inserted in the plasma membrane, glycosylated surface proteins were labeled with biotinylated concanavalin A (ConA) and isolated by streptavidin/agarose-mediated precipitation of the biotinyl-ConA-protein complex. Briefly, intact oocytes were incubated in $10 \mu \mathrm{m}$ biotinyl-ConA (Sigma-Aldrich, Munich, Germany) for $30 \mathrm{~min}$ at room temperature. After five $10 \mathrm{~min}$ washes in normal frog Ringer's solution, intact oocytes were homogenized in $\mathrm{H}$ buffer [ $20 \mu \mathrm{l} /$ oocyte; $100 \mathrm{~mm} \mathrm{NaCl}, 20 \mathrm{~mm}$ Tris-HCl, pH 7.4, 1\% Triton $\mathrm{X}-100$, plus a mixture of proteinase inhibitors (Complete tablets; Roche Molecular Biochemicals, Mannheim, Germany)] and were kept at $4^{\circ} \mathrm{C}$ for $1 \mathrm{~h}$ on a rotating rod. After centrifugation at $16,000 \times g$ for $15 \mathrm{~min}$, the supernatants were supplemented with $20 \mu \mathrm{l}$ of streptavidin/agarose beads (Fluka, Steinheim, Germany) and incubated at $4^{\circ} \mathrm{C}$ for $3 \mathrm{~h}$ on the rotating rod. The streptavidin/agarose beads were then pelleted by a 5 min spin at $16,000 \times g$ and washed three times in $\mathrm{H}$ buffer. The final pellets were boiled in $20 \mu \mathrm{l}$ of SDS-PAGE loading buffer ( $6 \mathrm{M}$ urea, $0.8 \mathrm{M}$ $\beta$-mercaptoethanol, $6 \%$ SDS, $20 \%$ glycerol, $25 \mathrm{~mm}$ Tris-HCl, pH 6.8, and $0.1 \%$ bromophenol blue).

Gel electrophoresis and Western blotting. Proteins were separated by SDS-PAGE using the Mini-Protean 3 system (Bio-Rad, Munich, Germany) and then electroblotted onto Hybond ECL nitrocellulose membranes (GE Healthcare). The nitrocellulose membranes were blocked with $1 \times$ Roti-Block (Roth, Karlsruhe, Germany) in TBS-T (140 mm $\mathrm{NaCl}, 20 \mathrm{~mm}$ Tris-HCl, pH 7.6, and $0.1 \%$ Tween 20), and detection of proteins was performed using rabbit anti-GluR1, which was a kind gift from Richard L. Huganir (Department of Neuroscience, Howard Hughes Medical Institute, The Johns Hopkins University School of Medicine, Baltimore, MD), and HRP-conjugated goat anti-rabbit (SigmaAldrich, Munich, Germany) antibodies. Blots were developed using ECL solutions (Pierce, Rockford, IL).

Electrophysiological measurements in human embryonic kidney 293 cells. Exponentially growing human embryonic kidney 293 (HEK293) cells were grown in Minimum Essential Medium Eagle, Joklik Modification (JMEM) (Sigma-Aldrich, Taufkirchen, Germany) supplemented with $10 \%$ fetal bovine serum (FBS) (Invitrogen, Paisley, UK) at $37^{\circ} \mathrm{C}, 8 \% \mathrm{CO}_{2}$ in polyornithine-coated $35 \mathrm{~mm}$ dishes. At $1 \mathrm{~h}$ before transfection, the cel culture medium was changed to DMEM (Invitrogen) supplemented with $10 \%$ FBS. Transfections were done using a modified calcium phosphate precipitation technique (Chen and Okayama, 1987). Briefly, cells were transfected with $3.0 \mu \mathrm{g}$ of DNA, with an equimolar ratio of AMPA receptor cDNA cloned into pcDNA3.0 and either $\gamma 2$-enhanced cyan fluorescent protein (ECFP)/pECFP-N1 or pECFP-N1. Transfections were performed for $8 \mathrm{~h}$ at $37^{\circ} \mathrm{C}$ with $3 \% \mathrm{CO}_{2}$. After incubation, the cells were washed with PBS before changing back to JMEM. After $48-72 \mathrm{~h}$ past transfection, whole-cell recordings were performed using an EPC-9 amplifier (HEKA Elektronik) controlled by Pulse 8.70 software (HEKA Elektronik). Currents were digitized with a sampling rate of $10 \mathrm{kHz}$ and filtered at $3 \mathrm{kHz}$. Recording pipettes were pulled from borosilicate glass (GC150TL-10; Harvard Apparatus, Edenbridge, UK) using a PIP5 pipette vertical puller (HEKA Elektronik) and had resistances of 4-8 $\mathrm{M} \Omega$. Agonists (3 mM glutamate or $600 \mu \mathrm{M}$ kainate) were prepared in extracellular solution and applied using a theta glass capillary (Hilgenberg) mounted on a piezo electric controller (Physik 
Instrumente, Karlsruhe, Germany) that bathed the suspended cell in a laminar flow for $200 \mathrm{~ms}$. The extracellular solution consisted of $140 \mathrm{~mm}$ $\mathrm{NaCl}, 4 \mathrm{~mm} \mathrm{KCl}, 2 \mathrm{~mm} \mathrm{CaCl}, 1 \mathrm{~mm} \mathrm{MgCl}_{2}$, and 10 mM HEPES-NaOH, pH 7.3; the pipette solution consisted of $130 \mathrm{~mm}$ CsF, $4 \mathrm{~mm} \mathrm{NaCl}, 1 \mathrm{~mm}$ $\mathrm{MgCl}_{2}, 0.5 \mathrm{mM} \mathrm{CaCl}_{2}, 11 \mathrm{~mm}$ EGTA, and $10 \mathrm{~mm}$ HEPES-KOH, pH 7.3. The current responses were measured at room temperature at a holding potential of $-60 \mathrm{mV}$. Current responses were filtered at $1-2 \mathrm{kHz}$ after recording.

\section{Results}

TARP-specific modulation of

GluR1(Q)flip is caused by differential

changes in electrophysiological properties and not receptor trafficking

Coexpression of GluR1(Q)flip with each of the four TARPs resulted in a robust potentiation of glutamate- and kainateevoked currents (Fig. 1A,B). Remarkably, this potentiation was strongly dependent on the particular TARP. $\gamma 2$ caused the strongest potentiation of glutamate- and kainate-induced steady-state currents (23.1 \pm 11.3 -fold, $n=6$, for glutamate and $71.8 \pm 13.2$-fold, $n=6$, for kainate), whereas $\gamma 8$ had the weakest effect $(2.2 \pm 0.4$-fold for glutamate and $14.5 \pm$ 3.2-fold for kainate, both $n=8$ ) (Fig. $2 B$ ). To clarify whether the different potentiation factors caused by each TARP were a consequence of differences in surface expression of GluR1(Q)flip subunits, we analyzed the amount of plasma membrane-resident GluR1(Q)flip. Western blots revealed that $\gamma 2$ and $\gamma 8$ led to an equally modest increase of approximately twofold in GluR1(Q)flip protein in the plasma membrane of Xenopus laevis oocytes, whereas coexpression of $\gamma 4$ had no effect on the amount of surface-incorporated GluR1 and coexpression of $\gamma 3$ even led to a small decrease of surface-incorporated GluR1(Q)flip (Fig. 1C). These findings were confirmed in three independent experiments, so that random oocyte variability can be excluded as the reason for the observed expression levels.

The limited alteration in plasma membrane-incorporated GluR1(Q)flip cannot explain some of the larger potentiation factors of agonist-induced currents. Moreover, the increase in current amplitudes differed strongly between the tested agonists glutamate and kainate. Each of the four TARPs potentiated kainateinduced currents much stronger than glutamate-induced currents, resulting in an increase in the ratio of kainate- to glutamate-induced currents $\left(I_{\mathrm{KA}} / I_{\mathrm{Glu}}\right.$ ratio) (Table 1$)$. This shift in the $I_{\mathrm{KA}} / \mathrm{I}_{\mathrm{Glu}}$ ratio was dependent on the coexpressed TARP, leading to $I_{\mathrm{KA}} / I_{\mathrm{Glu}}$ ratios between $3.2 \pm 0.6(n=6,+\gamma 4)$ and $15.0 \pm 5.1(n=6,+\gamma 2)$ compared with $1.9 \pm 0.3(n=5)$ determined for GluR1(Q)flip expressed in the absence of any TARP. It has been described previously that $\gamma 2$ shifts the $\mathrm{EC}_{50}$ values for glutamate and kainate to lower concentrations (Yamazaki et al., 2004; Priel et al., 2005; Tomita et al., 2005; Turetsky et al., 2005). Here, we determined that all four TARPs reduce $\mathrm{EC}_{50}$ values for glutamate and to different extents (Fig. 1D). $\gamma 2$ and $\gamma 3$ behave similarly, shifting the $\mathrm{EC}_{50}$ for glutamate from

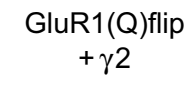
GluR1(Q)flip
$+\gamma 3$
GluR1(Q)flip
$+\gamma 4$

GluR1(Q)flip

$+\gamma 8$
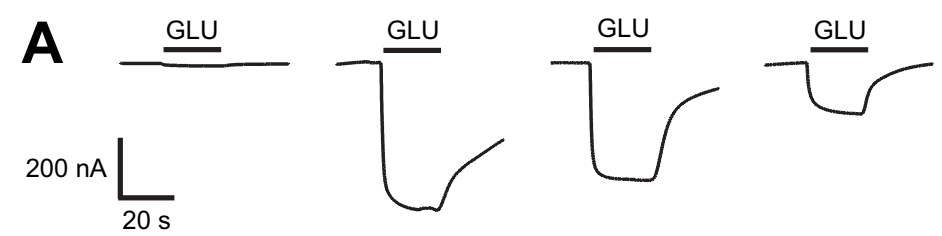

$\underline{\text { GLU }}$
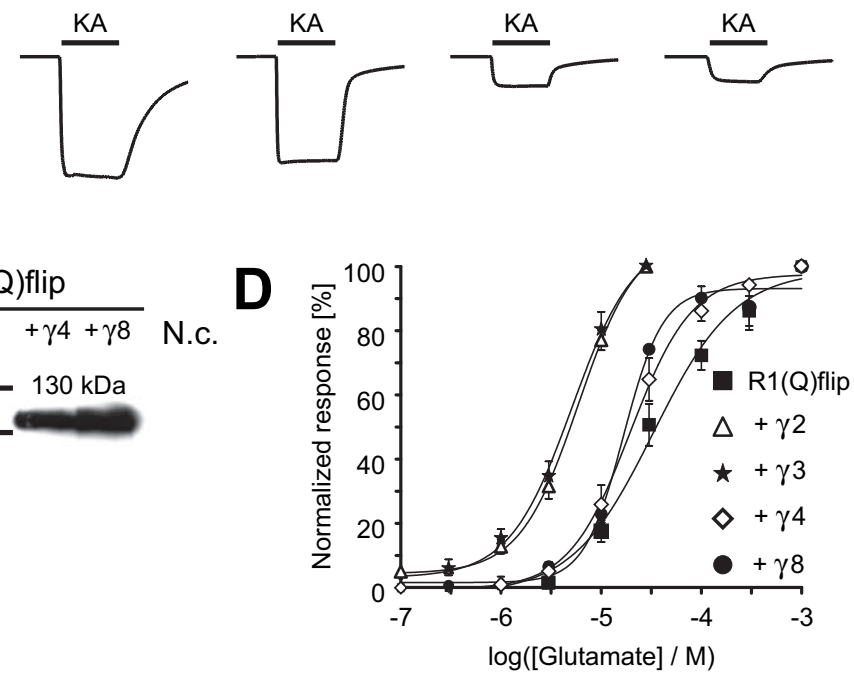

Figure 1. Coexpression of TARPs differentially enlarges agonist-induced currents of GluR1(Q)flip. $\boldsymbol{A}, \boldsymbol{B}$, Glutamate-induced ( $\boldsymbol{A}$ ) and kainate-induced $(\boldsymbol{B})$ responses of GluR1(Q)flip alone and in combination with each of the four TARPs were recorded from Xenopus 0ocytes in magnesium Ringer's solution. The application of agonists ( $300 \mu \mathrm{m} \mathrm{Glu} \mathrm{or} 150 \mu \mathrm{M} \mathrm{KA}$ ) is indicated by black bars. ocytes (N.c.) served as control for cross-reactivity of the antibodies. D, Dose-response curves for the agonist L-glutamate were determined from oocytes injected with cRNAs of GluR1(Q)flip alone and in combination with each of the four TARPs. Values are means \pm SEM $(n=4-6)$, normalized to the maximal responses. The $\mathrm{EC}_{50}$ values are given in Results.

$37.2 \pm 9.0 \mu \mathrm{M}(n=4)$ determined for GluR1(Q)flip alone to $6.0 \pm$ $0.6 \mu \mathrm{M}(n=5 ; p<0.01)$ and $5.3 \pm 0.7 \mu \mathrm{M}(n=4 ; p<0.01)$, respectively. Coexpressions of $\gamma 8$ or $\gamma 4$ led to a considerably less pronounced shift of the $\mathrm{EC}_{50}$ for glutamate compared with $\gamma 2$ or $\gamma 3$, with $20.3 \pm 3.3 \mu \mathrm{M}[n=4 ; p<0.05$ compared with GluR1(Q)flip and $p<0.005$ compared with GluR1(Q)flip $+\gamma 2$ ] for $\gamma 4$ and $16.8 \pm$ $0.4 \mu \mathrm{M}[n=3 ; p<0.05$ compared with GluR1(Q)flip and $p<0.005$ compared with GluR1(Q)flip + $\gamma 2$ ] for $\gamma 8$.

\section{Differential impact of the flip/flop domains of AMPA} receptors on the TARP-mediated increase in agonist-induced currents

Next, we analyzed whether the TARP-specific impact on agonistinduced currents may depend on the splice variant of the associated AMPA receptor. Similar to GluR1(Q)flip, GluR1(Q)flopmediated currents were increased by all members of the TARP family and, as observed for GluR1(Q)flip, to different extents (Fig. 2A). $\gamma 2, \gamma 3$, and $\gamma 4$ boosted glutamate-induced currents at the GluR1(Q)flop splice variant most effectively, whereas coexpression of $\gamma 8$ resulted in a relatively small current potentiation. Kainate-induced currents were affected maximally by $\gamma 2$ and $\gamma 3$ $(\sim 220$-fold for $\gamma 2$ and 300-fold for $\gamma 3$ ). Coexpression with $\gamma 4$ or $\gamma 8$ resulted in a less potent increase in kainate-induced currents but still produced potentiation factors of $\sim 100$-fold. In contrast to the flip variant, glutamate-induced responses of GluR1(Q)flop were more strongly potentiated by $\gamma 2$ and $\gamma 4$ than kainate- 

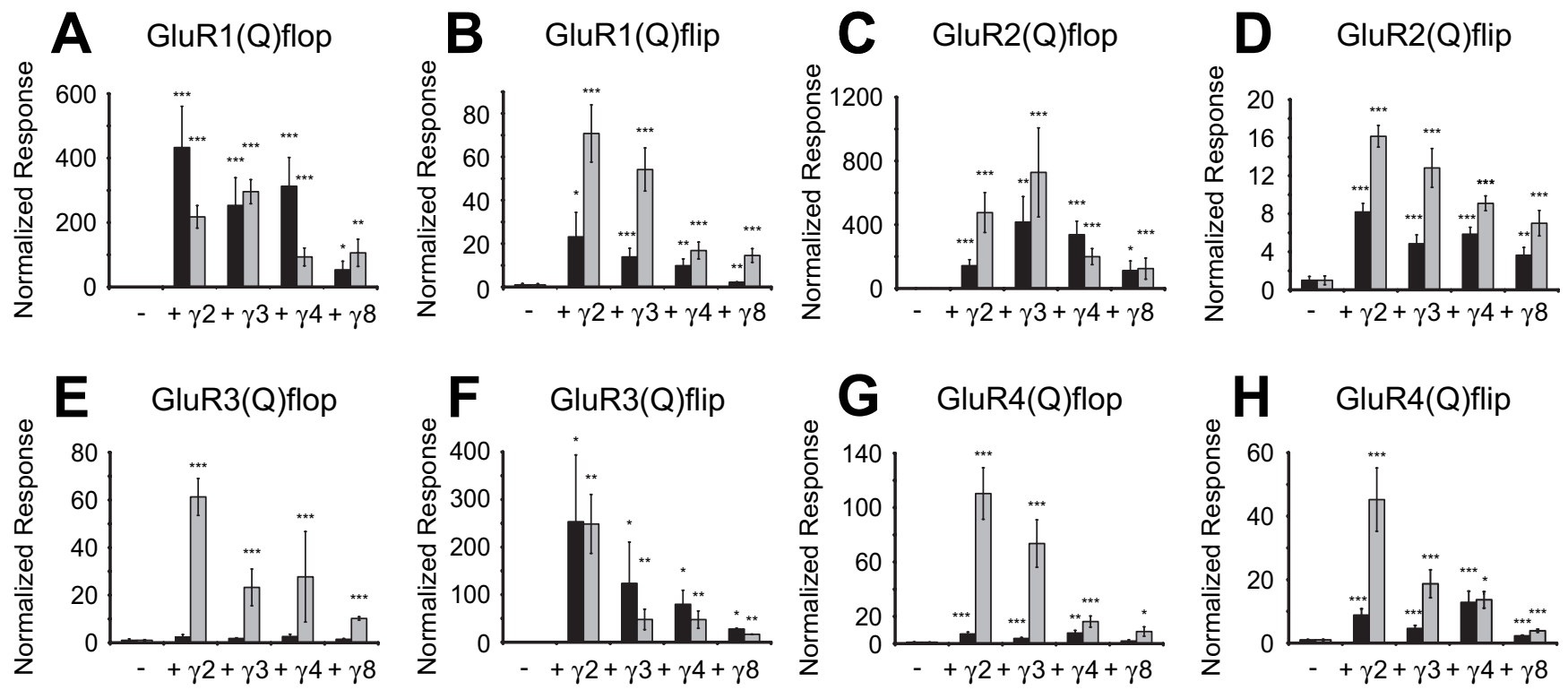

Figure 2. Increase in agonist-induced currents of AMPA receptors during coexpression of TARPs. Glutamate-induced (300 $\mu \mathrm{m}$; black columns) and kainate-induced (150 $\mu \mathrm{m}$; gray columns) responses of AMPA receptors alone and in combination with each of the four TARPs were recorded from Xenopus oocytes in magnesium Ringer's solution. In the top row, GluR1 $(\boldsymbol{A}, \boldsymbol{B})$ and $G$ luR2 $(\boldsymbol{C}$, D) are depicted compared with GluR3 $(\boldsymbol{E}, \boldsymbol{F})$ and GluR4 $(\boldsymbol{G}, \boldsymbol{H})$ in the bottom row. For quantification, agonist-induced currents of all eight AMPA receptors in coexpression with a TARP were normalized to the responses mediated by the respective AMPA receptor subunit expressed without TARP. Data are shown $\pm \operatorname{SEM}(n=5-12) .{ }^{*} p<0.05$; ${ }^{* *} p<0.01$; ${ }^{* * *} p<0.005$ (Student'st test) compared with the respective AMPA receptor subunit expressed without TARP.

Table 1. Coexpression of TARPs leads to a shift of $I_{\mathrm{KA}} I_{\mathrm{Glu}}$ ratios of homomerically expressed AMPA receptor subunits

\begin{tabular}{|c|c|c|c|c|c|c|c|c|c|}
\hline & GluR1(Q) & $\operatorname{GluR1}(Q)_{i}$ & GluR2 $(Q)_{0}$ & $\operatorname{GluR2}(Q)_{\mathrm{i}}$ & GluR2(R) & GluR3(Q) & $\operatorname{GluR3}(Q)_{\mathrm{i}}$ & GluR4(Q) & $\operatorname{GluR4}(Q)_{\mathrm{i}}$ \\
\hline - & $4.2 \pm 0.6$ & $1.9 \pm 0.3$ & $5.2 \pm 1.4$ & $0.6 \pm 0.1^{* * *}$ & $0.7 \pm 0.1$ & $1.3 \pm 0.3$ & n.d. ${ }^{a}$ & $17.8 \pm 5.1$ & $3.7 \pm 0.8$ \\
\hline$\gamma_{2}$ & $15.7 \pm 4.0^{* *}$ & $15.0 \pm 5.1^{*}$ & $28.3 \pm 6.5^{* *}$ & $1.4 \pm 0.1^{* * *}$ & $1.3 \pm 0.1^{* * *}$ & $33.3 \pm 8.4^{*}$ & $16.4 \pm 4.3$ & $215 \pm 26^{* * *}$ & $22.6 \pm 2.5^{* * *}$ \\
\hline$\gamma^{3}$ & $17.2 \pm 7.1^{*}$ & $8.8 \pm 2.2^{*}$ & $18.0 \pm 4.4^{*}$ & $2.0 \pm 0.1^{* * *}$ & $1.3 \pm 0.0^{* * *}$ & $17.6 \pm 8.6^{*}$ & $15.5 \pm 6.0$ & $180 \pm 22^{* * *}$ & $29.4 \pm 3.8^{* * *}$ \\
\hline$\gamma 4$ & $2.0 \pm 0.3^{*}$ & $3.2 \pm 0.6$ & $4.9 \pm 0.8$ & $1.2 \pm 0.1^{* * *}$ & $1.7 \pm 0.3^{*}$ & $7.8 \pm 3.2^{*}$ & $4.9 \pm 0.3$ & $27.8 \pm 3.1$ & $4.7 \pm 0.5$ \\
\hline$\gamma 8$ & $13.7 \pm 2.8^{* * *}$ & $10.0 \pm 1.3^{* *}$ & $12.7 \pm 2.6^{*}$ & $1.4 \pm 0.1^{* * *}$ & $2.7 \pm 0.2^{* * *}$ & $5.5 \pm 0.2^{* * *}$ & $5.7 \pm 0.5$ & $69.6 \pm 11.9^{* * *}$ & $7.4 \pm 0.8^{* *}$ \\
\hline
\end{tabular}

The ratios of kainate- to glutamate-induced currents $\left(I_{\mathrm{KA}} I_{\mathrm{Glu}}\right.$ ratio) were calculated for each oocyte and averaged ( \pm SEM). Concentrations of the applied agonists were $150 \mu \mathrm{M}$ for kainate and $300 \mu \mathrm{M}$ for glutamate. GluR1( $(\mathrm{Q})_{0}, \mathrm{GluR} 1(\mathrm{Q})$ flop GluR2(R) i, GluR2(R)flip. ${ }^{*} p<0.05 ;{ }^{* *} p<0.01 ;{ }^{* * *} p<0.005$. n.d., Not determined.

${ }^{a}$ Because of small agonist-induced currents, $I_{\mathrm{KA}} / I_{\mathrm{Glu}}$ ratios could not be calculated; therefore, no significances could be determined for the ratios in this column.

induced currents (Fig. 2A). In general, the increase of agonistinduced currents by TARPs was larger for GluR1(Q)flop than for GluR1(Q)flip. Depending on the coexpressed TARP, the difference between potentiation factors of GluR1(Q)flop compared with GluR1(Q)flip varied from 3-fold to 10-fold for kainateinduced currents and from $\sim 2$-fold to 30 -fold for glutamateinduced currents.

An even more pronounced difference in the TARP influence on agonist-induced currents can be seen between the flop and flip splice variants of GluR2. The impact of TARPs on kainateinduced currents of GluR2(Q)flop was 30-fold larger than for the flip isoform coexpressed with the same TARP (Fig. $2 C, D$ ). For glutamate-induced currents, the difference between potentiation factors for the flop and flip isoforms was even larger, at values $\sim 100$-fold.

However, despite the larger impact of TARPs on the flop isoforms of GluR1 and GluR2, steady-state agonist-induced currents of the flop isoforms still remained smaller than those of the respective flip isoforms when coexpressed with the same TARP. Consequently, coexpression of a TARP decreases the difference between the steady-state amplitudes of agonist-induced currents of flop and flip isoforms.

The differences in modulation of GluR1(Q) and GluR2(Q) by TARPs suggested an AMPA receptor subunit-dependent mechanism of modulation. Therefore, we extended our investigation to the other unedited AMPA receptor subunits, GluR3 and GluR4, analyzing flip and flop splice variants of each subunit.

In contrast to the results for GluR1 and GluR2, TARPs enhanced currents mediated by the flip variant of GluR3 more strongly than currents of the flop variant (Fig. 2E,F). A second difference from GluR1 and GluR2 was that glutamate-induced currents mediated by GluR3(Q)flop were potentiated very weakly compared with kainate-induced currents (Fig. 2E). In contrast, glutamate-induced currents of GluR3(Q)flip were potentiated higher or at least to the same extent as kainate-induced currents (Fig. $2 F$ ). Also, potentiation factors of kainate-induced currents were approximately fivefold and those of glutamateinduced currents up to 30-fold larger for GluR3(Q)flip than for GluR3(Q)flop. Larger potentiation factors for the flip variants than for the flop variants were not observed for any other AMPA receptor subunit, which indicates to be a unique property of GluR3. Another factor distinguishing GluR3 from GluR1 and GluR2 is the impact of $\gamma 3$. This TARP increases current amplitudes of GluR1 and GluR2 strongly, to an extent comparable with $\gamma 2$, whereas it enlarges agonist-induced currents of GluR3 to a lesser extent, comparable with the potentiation by $\gamma 4$. For GluR3, as shown before for GluR1 and GluR2, $\gamma 8$ was the least efficient of all TARPs with respect to the potentiation of agonist-induced currents.

Glutamate-induced currents of GluR4(Q)flop were enhanced 
very weakly by coexpression of any TARP, similar to what was observed for GluR3(Q)flop (Fig. 2G). Kainate-induced currents, however, were increased efficiently, and, in contrast to GluR3(Q)flop, $\gamma 3$ had a similar potency as $\gamma 2$ to enlarge kainate-induced currents of GluR4(Q)flop. This preferential enhancement of kainateinduced currents seen for GluR4(Q)flop resulted in a dramatic increase of the $I_{\mathrm{KA}} /$ $I_{\mathrm{Glu}}$ ratios, which to this extent was not seen with any other homomerically expressed AMPA receptor (Table 1). The largest shift in the $I_{\mathrm{KA}} / I_{\mathrm{Glu}}$ ratio was observed for the combination of GluR4(Q)flop and $\gamma 2$, as evidenced by an increase from $17.8 \pm 5.1(n=10)$ deter-

mined for GluR4(Q)flop expressed without any TARP to $215.3 \pm$ $26.7(n=12)$. For the GluR4(Q)flip subunit, $I_{\mathrm{KA}} / I_{\mathrm{Glu}}$ ratios were also increased during coexpression with a TARP but to a lesser extent than for the flop isoform. The largest shift was seen for the combination with $\gamma 3$, which led to a value of $29.4 \pm 3.8(n=10)$ compared with $3.7 \pm 0.8(n=10)$ determined for GluR4(Q)flip expressed without any TARP (Table 1). Although impacts of TARPs on glutamate-induced currents (very weakly enhanced) and kainate-induced currents (strongly enhanced) were similar for GluR4(Q)flop and GluR3(Q)flop, we did not observe a comparable impact of TARPs on the flip splice variants of GluR4(Q) and GluR3(Q) (Fig. 2F,H). TARPs are known to decrease the extent of receptor desensitization (Priel et al., 2005; Tomita et al., 2005; Turetsky et al., 2005), thus increasing glutamate-induced steady-state currents of AMPA receptors. Therefore, we investigated whether the very weak enhancement of glutamate-induced steady-state currents of GluR3(Q)flop and GluR4(Q)flop by $\gamma 2$ is correlated to a similarly weak inhibition of receptor desensitization. Therefore, we analyzed current responses of GluR3(Q)flop and GluR4(Q)flop in the presence or absence of $\gamma 2$ by whole-cell patch-clamp recordings in HEK293 cells (Fig. 3A). We found a clear increase of $\sim 80$-fold $(n=3-5)$ in the kainate-induced peak currents of GluR3(Q)flop coexpressed with $\gamma 2$ compared with GluR3(Q)flop expressed alone. Additionally, the extent of desensitization of GluR3(Q)flop was not significantly altered by coexpression of $\gamma 2$ (Fig. 3B). For the other examined subunit GluR4(Q)flop, we observed similar results: kainate-induced peak currents were potentiated $\sim 140$-fold $(n=6)$, and the extent of desensitization was not significantly altered by coexpression of $\gamma 2$ (Fig. 3B). Thus, the results of patch-clamp recordings from HEK293 cells confirmed the weak potentiation of glutamateinduced and the large potentiation of kainate-induced steadystate currents of GluR3(Q)flop and GluR4(Q)flop by coexpression of TARPs observed in Xenopus oocytes.

\section{Influence of the $Q / R$ site amino acid on the TARP-mediated enhancement of agonist-induced currents}

Next, we focused on the potential influence of the amino acid at the $\mathrm{Q} / \mathrm{R}$ editing site on TARP-mediated current modulation. Therefore, we compared the influence of TARPs on the physiologically edited AMPA receptor subunit GluR2(R)flip and the engineered, unedited subunit GluR2(Q)flip. Although agonistinduced currents of both isoforms were increased by each TARP, responses of GluR2(R)flip showed a much stronger potentiation than those of GluR2(Q)flip (Figs. 2D, 4A). For GluR2(R)flip, the ability of the TARPs to enhance agonist-induced currents was pronounced for $\gamma 2$ and $\gamma 3$ and weak for $\gamma 8$ and $\gamma 4$. Potentiation factors for glutamate-induced currents ranged from $22.7 \pm 10.7$ $(n=8)$ for coexpression with $\gamma 4$ to $227.6 \pm 65.7(n=7)$ for coexpression with $\gamma 2$ (Fig. $4 A$ ). For kainate-induced currents the potentiation factors ranged from $34.6 \pm 14.4(n=8)$ when GluR2(R)flip was coexpressed with $\gamma 4$ to $306.5 \pm 84.1(n=7)$ during coexpression with $\gamma 2$. Compared with GluR2(R)flip, the potentiation factors for GluR2(Q)flip were $\sim 20$-fold smaller (Fig. $2 D$ ). TARPs had only little influence on the $I_{\mathrm{KA}} / I_{\mathrm{Glu}}$ ratios of both unedited $(\mathrm{Q})$ and edited (R) GluR2flip, leading to a small shift from $0.7 \pm 0.1$ determined for GluR2(R)flip $(n=5)$ to $2.7 \pm 0.2$ determined for GluR2(R)flip in coexpression with $\gamma 8$ $(n=8)$ (Table 1$)$.

\section{Modulation of heteromeric AMPA receptor assemblies by TARPs depends on the subunit composition}

In the CNS of vertebrates, AMPA receptors are generally expressed as heteromers mainly built from combinations of GluR1 or GluR3 with an edited GluR2 variant (Wenthold et al., 1996). In addition, functional receptor complexes in most cases contain both splice isoforms (Mansour et al., 2001; Brorson et al., 2004). Therefore, we examined three physiologically relevant combinations of AMPA receptor subunits, GluR1(Q)flop with GluR2(R)flip, GluR3(Q)flop with GluR2(R)flip, and GluR1(Q)flip with GluR4(Q)flip, in coexpression with each of the four TARPs (Fig. $4 B-D)$. The assembly of heteromeric receptor complexes containing both unedited $(\mathrm{Q})$ and edited $(\mathrm{R})$ receptor variants was verified by analysis of current-voltage relationships. Only oocytes that showed a linear current-voltage relationship with reversal potentials ranging from 0 to $-10 \mathrm{mV}$ were included in the statistics. Oocytes showing glutamate-induced currents below $20 \mathrm{nA}$ were excluded from the statistics because of potential expression of homomeric GluR2(R)flip. The rectifying current-voltage relationships of GluR1(Q)flip/GluR4(Q)flip could not be used to prove heteromeric assembly. Therefore, the assembly of GluR1(Q)flip with GluR4(Q)flip was confirmed by comparing the amplitudes of agonist-induced responses of coexpressed subunits to responses measured for homomerically expressed GluR1(Q)flip and GluR4(Q)flip receptors in the same preparation of oocytes.

A clear enhancement of agonist-induced currents by TARPs was observed for the coexpression of GluR1(Q)flop with GluR2(R)flip (Fig. $4 B$ ). To our surprise, $\gamma 4$ increased glutamateinduced currents stronger than all other TARPs (125 \pm 18 -fold; $n=10)$. The increase of glutamate-induced currents was weaker for $\gamma 2$ (76 \pm 13 -fold; $n=14 ; p<0.05$ compared with $\gamma 4$ ) and weakest for $\gamma 3$ and $\gamma 8$, with potentiation factors of $23 \pm 5(n=$ 

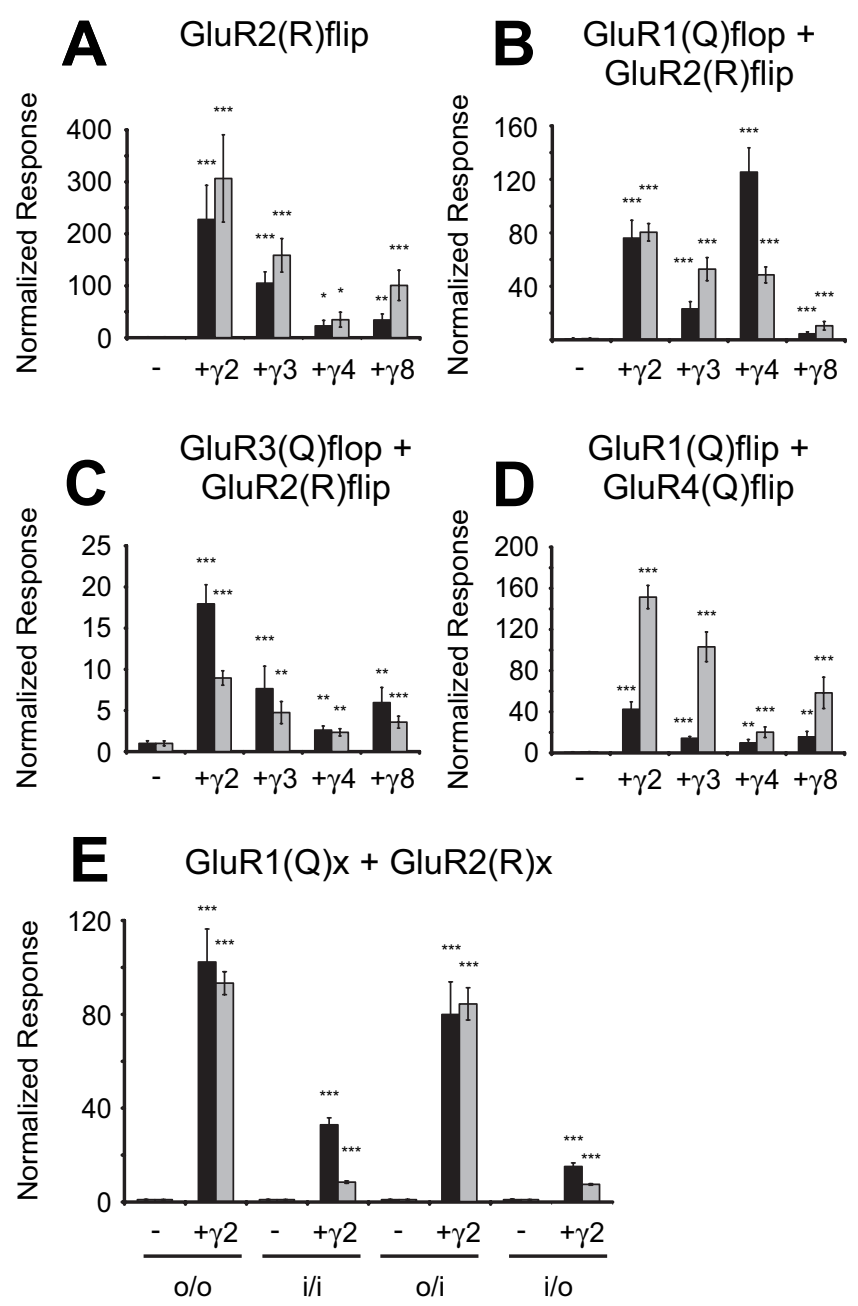

Figure 4. Comparison of the current amplitude-modulating effects of TARPs on GluR2(R)flip and several heteromeric AMPA receptors. $\boldsymbol{A}-\boldsymbol{D}$, Identical amounts of GluR2(R)flip $(\boldsymbol{A})$, GluR1(Q)flop/GluR2(R)flip (B), GluR3(Q)flop/GluR2(R)flip (C), and GluR1(Q)flip/GluR4(Q)flip (D) CRNAs were coinjected with each TARP, and agonist-induced currents were recorded $4-6 \mathrm{~d}$ after injection. Glutamate-induced (300 $\mu \mathrm{m}$; black columns) and kainate-induced (150 $\mu \mathrm{m}$; gray columns) responses of AMPA receptors alone and in combination with each of the four TARPs were recorded from Xenopus oocytes in magnesium Ringer's solution. Normalization was performed as described in Figure $2\left({ }^{*} p<0.05 ;{ }^{* *} p<0.01 ;{ }^{* * *} p<0.005\right)$. E, Glutamateinduced (300 $\mu \mathrm{m}$; black columns) and kainate-induced (150 $\mu \mathrm{m}$; gray columns) responses of heteromeric GluR1(Q)/GluR2(R) combinations in the absence and presence of $\gamma 2$ were recorded from Xenopus 0ocytes. Normalization was performed as described in Figure $2\left({ }^{*} p<0.05\right.$; ${ }^{* *} p<0.01 ;{ }^{* *} p<0.005$ compared with the respective heteromeric AMPA receptor expressed without $\gamma 2$ ). The given combination of contributing splice variants is indicated by the abbreviations listed below the $x$-axis: $0 / 0, \quad G l u R 1(Q) f l o p / G l u R 2(R) f l o p ; i / 0$, GluR1(Q)flip/GluR2(R)flop.

10) for $\gamma 3$ and $5 \pm 1(n=18)$ for $\gamma 8$. Kainate-induced currents of GluR1(Q)flop/GluR2(R)flip were potentiated strongest by $\gamma 2$ ( $80 \pm 7$-fold; $n=11$ ) and to a slightly smaller extent by $\gamma 3$ and $\gamma 4$ (53 \pm 9 -fold for $\gamma 3$ and $49 \pm 6$-fold for $\gamma 4$; both $n=10 ; p<0.01$ compared with $\gamma 2$ ). Coexpression of $\gamma 8$ had the weakest influence on kainate-induced currents ( $11 \pm 3$-fold; $n=18)$. Simultaneously, the influence of TARPs on the $I_{\mathrm{KA}} / I_{\mathrm{Glu}}$ ratios of GluR1(Q)flop/GluR2(R)flip varied from a decrease observed for the coexpression with $\gamma 4$ to a small increase observed for $\gamma 3$ and $\gamma 8$ (Table 2). Next, we investigated to which degree the impact of TARPs on heteromeric receptors such as GluR1(Q)/GluR2(R) is dependent on the splice variants of the contributing subunits. To this end, all possible combinations that can arise from GluR1(Q) and GluR2(R) in either the flop or the flip splice forms were tested in the presence or absence of $\gamma 2$. We detected a clear dependence of the impact of $\gamma 2$ on the splice variant composition of receptor complexes. As observed before for the homomerically expressed GluR1(Q) and GluR2(Q) subunits, agonist-induced currents of receptors composed of only flop-spliced subunits were more strongly potentiated by $\gamma 2$ than the responses of flip-spliced receptors (Fig. 4E). The impact of $\gamma 2$ on heteromeric receptors containing both splice variants depended on which AMPA receptor subunit was flip spliced (Fig. $4 E$ ). In contrast to the nearly equal enlargement of glutamate- and kainate-induced currents of GluR1(Q)flop/GluR2(R)flip by coexpression of $\gamma 2$, glutamateinduced currents of the combination GluR1(Q)flip/ GluR2(R)flop were more strongly potentiated than kainateinduced currents $(15 \pm 2$-fold for glutamate and $8 \pm 0$-fold for kainate; both $n=6$ ). Not only the potentiation of agonistinduced currents but also the direction and the extent of the shift in the ratio between kainate- and glutamate-induced currents caused by coexpression of $\gamma 2$ were dependent on the splice variant composition of heteromeric receptors. For GluR1(Q)/ GluR2(R) heteromers composed of only flop variants, as described previously for GluR1(Q)flop/GluR2(R)flip, we detected no significant change in the $I_{\mathrm{KA}} / I_{\mathrm{Glu}}$ ratios when $\gamma 2$ was coexpressed (Table 3). When GluR1(Q)flip contributed to the heteromeric complex, we observed a decrease of the $I_{\mathrm{KA}} / I_{\mathrm{Glu}}$ ratios during coexpression of $\gamma 2$. Thus, our data are in line with a previous report by Turetsky et al. (2005), who also showed a reduction of $I_{\mathrm{KA}} / I_{\mathrm{Glu}}$ ratios by $\gamma 2$ (if steady-state currents are compared) of selected splice variant combinations of heteromeric receptors built from GluR1(Q) and GluR2(R). However, that study did not include the combination of GluR1(Q)flop/GluR2(R)flip investigated here, which showed no reduction of the $I_{\mathrm{KA}} / I_{\mathrm{Glu}}$ ratio by $\gamma 2$ but, as demonstrated previously, showed a strong dependence on the coexpressed TARP in the shift of $I_{\mathrm{KA}} / I_{\mathrm{Glu}}$ ratios.

For the heteromeric combination of GluR3(Q)flop/ GluR2(R)flip, we detected a clear potentiation by all four TARPs (Fig. 4C). $\gamma 2$ enhanced glutamate-induced currents $17.9 \pm 2.3$ fold $(n=6)$ and kainate-induced currents $8.9 \pm 0.9$-fold $(n=6)$. $\gamma 3, \gamma 4$, and $\gamma 8$ potentiated agonist-induced currents of GluR3(Q)flop/GluR2(R)flip heteromers weaker than $\gamma 2[p<$ 0.05 compared with GluR3(Q)flop/GluR2(R)flip $+\gamma 2$ ]. Interestingly, for the combination GluR3(Q)flop/GluR2(R)flip, TARPs caused equal or larger potentiation of glutamate-induced currents than of kainate-induced currents, similar to what we had observed previously for GluR3(Q)flip. Strikingly, both contributing subunits, GluR2(R)flip and GluR3(Q)flop, did not show such a behavior when they were investigated individually as homomerically expressed receptors (Figs. $2 E, 4 A$ ). Coexpression of TARPs dropped the $I_{\mathrm{KA}} / I_{\mathrm{Glu}}$ ratio of GluR3(Q)flop/GluR2(R)flip from $13.1 \pm 1.2(n=9)$ (without TARPs) to values between $11.4 \pm 0.7(\gamma 4 ; n=8)$ and $6.7 \pm 0.4(\gamma 2 ; n=6)$ (Table 2).

For the heteromeric combination GluR1(Q)flip/GluR4(Q)flip, we observed strongly enlarged kainate-induced currents during coexpression with a TARP, with potentiation factors ranging from $20.2 \pm 5.1(\gamma 4 ; n=10)$ to $151.4 \pm 11.3$-fold $(\gamma 2 ; n=9)$. The enlargement of glutamate-induced currents of GluR1(Q)flip/ GluR4(Q)flip was most pronounced for $\gamma 2$ (42.4 \pm 7.3-fold; $n=9$ ), whereas the other TARPs caused a smaller potentiation of glutamate-induced currents (Fig. 4D). We saw a TARP-dependent increase in the $I_{\mathrm{KA}} / I_{\mathrm{Glu}}$ ratios for this combination (Table 2). The strongest shift was induced by coexpression with $\gamma 3$, which increased the ratio from $2.6 \pm 0.8(n=11)$ to $17.8 \pm 1.9(n=9)$. 


\section{The extent of TARP-mediated reduction of AMPA receptor desensitization is primarily determined by the interacting TARP}

Coexpression of $\gamma 2$ (and also $\gamma 3$ ) has been reported to result in altered electrophysiological properties of AMPA receptors, predominantly by decreasing receptor desensitization (Priel et al., 2005; Tomita et al., 2005; Turetsky et al., 2005), and by increasing the relative efficacy for the partial agonist kainate (Tomita et al., 2005). To allow for a quantitative estimation of these two effects, we analyzed the action of $\gamma 2$ on the virtually nondesensitizing L479Y mutant of GluR1(Q)flip (Stern-Bach et al., 1998; Sun et al., 2002). In a recent publication, it was stated that $\gamma 2$ led to an increase in surface-expressed receptor protein for the flip-spliced variant of GluR1-L479Y but, at the same time, did not increase glutamateinduced currents (Tomita et al., 2007). However, this conclusion was derived from measurements performed with a nonsaturating concentration of glutamate, and glutamate-induced currents of the mutant construct had smaller amplitudes than the investigated wild-type subunit, a finding that cannot be reconciled with the well known characteristics of the LY mutant. In our hands, GluR1(Q)flip-L479Y evoked larger glutamate-induced responses than the wild type. Furthermore, agonist-induced currents of this receptor mutant are actually enlarged by coexpression with $\gamma 2$, because glutamate-induced currents were increased by a factor of $1.7 \pm 0.2(n=6)$ and kainate-induced currents by a factor of $11.0 \pm 1.5(n=5)$. Therefore, we conclude from our data that the L479Y mutation in GluR1 does not lead to an alternative mechanism of TARP interaction as postulated by Tomita et al. (2007). To support this conclusion, we analyzed the three other TARPs in combination with GluR1(Q)flip-L479Y. Glutamate-induced currents were enlarged by all TARPs to an equal extent, whereas kainate-induced currents were enlarged strongly by $\gamma 2$ and $\gamma 3$, less by $\gamma 4(p<0.05$ compared with coexpression with $\gamma 2$ ), and only weakly by $\gamma 8$ ( $p<0.01$ compared with coexpression with $\gamma 4$ ) (Fig. 5A). The observed proportionally stronger enhancement of kainate- versus glutamateinduced currents of GluR1(Q)flip-L479Y led to an increase in the $I_{\mathrm{KA}} / I_{\mathrm{Glu}}$ ratio from $0.08 \pm 0.01$ to $0.50 \pm 0.02$ for $\gamma 2$ and to $0.53 \pm$ 0.02 for $\gamma 3$ (both $n=5$ ) (Fig. 5B). Correlating with their weaker impact on kainate-induced currents, $\gamma 4$ shifted the $I_{\mathrm{KA}} / I_{\mathrm{Glu}}$ ratio to a value of $0.39 \pm 0.03(n=6 ; p<0.05$ compared with coexpression with $\gamma 2)$ and $\gamma 8,0.20 \pm 0.01(n=5 ; p<0.005$ compared with coexpression with $\gamma 4$ ) (Fig. $5 B$ ). Because receptor desensitization is virtually abolished by the introduction of the L479Y mutation (Stern-Bach et al., 1998; Sun et al., 2002) and because all TARPs lead to a similar increase in glutamate-induced currents of GluR1(Q)flip-L479Y, our observations indicate that the TARP-dependent differences in potentiation of glutamateinduced currents for the wild-type subunit must be attributable to different levels of TARP-mediated inhibition of receptor desensitization. Additionally, the increase of kainate-induced currents was slightly dependent on the coexpressed TARP, even in the nondesensitizing mutant, which emphasizes again that TARP modulation is an agonist-dependent mechanism. The increase of kainate-induced currents is one of the prominent effects of the electrophysiological modulation of AMPA receptors by TARPs. However, the diverse $I_{\mathrm{KA}} / I_{\mathrm{Glu}}$ ratios of GluR1(Q)flip-L479Y in coexpression with the different TARPs indicates that the socalled apparent efficacy for the partial agonist kainate is not en-
Table 3. The splice variant combination in heteromeric receptor complexes determines the impact of $\gamma 2$ on $I_{\mathrm{KA}} / I_{\mathrm{Glu}}$ ratios

\begin{tabular}{lllll}
\hline & $\begin{array}{l}\text { GluR1 }(Q)_{0}+ \\
\operatorname{GluR2}(\mathrm{R})_{0}\end{array}$ & $\begin{array}{l}\text { GluR1(Q) } \\
\operatorname{GluR2}(\mathrm{R})_{\mathrm{i}}\end{array}$ & $\begin{array}{l}\mathrm{GluR1}(\mathrm{Q})_{0}+ \\
\mathrm{GluR2}(\mathrm{R})_{\mathrm{i}}\end{array}$ & $\begin{array}{l}\mathrm{GluR1}(\mathrm{Q})_{\mathrm{i}}+ \\
\operatorname{GluR2}(\mathrm{R})_{0}\end{array}$ \\
\hline- & $37.5 \pm 2.0$ & $7.8 \pm 0.9$ & $5.6 \pm 0.3$ & $20.8 \pm 2.3$ \\
$\gamma 2$ & $41.9 \pm 3.5$ & $1.9 \pm 0.1^{*}$ & $5.4 \pm 0.5$ & $8.4 \pm 1.0^{*}$ \\
\hline
\end{tabular}

Calculation was performed as described for Table 1. The nomenclature of the AMPA receptor subunits is explained in Table 1. $n=15-16 .{ }^{*} p<0.005$ compared with AMPA receptor subunits without TARP.

larged to a degree comparable with the full agonist glutamate, because the $I_{\mathrm{KA}} / I_{\mathrm{Glu}}$ ratios have values below one.

Previous publications (Priel et al., 2005; Tomita et al., 2005; Turetsky et al., 2005) correlated the leftward shift in the doseresponse relationship of AMPA receptors by $\gamma 2$ with the inhibition of desensitization. We determined the $\mathrm{EC}_{50}$ values for glutamate for GluR1(Q)flip and GluR1(Q)flip-L479Y expressed alone and in combination with $\gamma 2$. As described previously (Stern-Bach et al., 1998), introduction of the L479Y mutation led to a reduction of the $\mathrm{EC}_{50}$ value for glutamate compared with the wild-type subunit from 37.2 $\pm 9.0 \mu \mathrm{M}(n=4)$ to $10.4 \pm 0.9 \mu \mathrm{M}[n=3$; $p<$ 0.05 compared with GluR1(Q)flip] (Fig. 5C). Contrary to Priel et al. (2005), we found an additional decrease of the $\mathrm{EC}_{50}$ value for glutamate from $10.4 \pm 0.9$ to $2.2 \pm 0.7 \mu \mathrm{M}$ [both $n=4 ; p<0.005$ compared with GluR1(Q)flip-L479Y] when $\gamma 2$ was coexpressed with GluR1(Q)flip-L479Y. Notably, this $\mathrm{EC}_{50}$ value was virtually identical to the one obtained for the simultaneously investigated wild-type subunit in coexpression with $\gamma 2$ (Fig. 5C).

Another approach to block desensitization in AMPA receptors is the application of $100 \mu \mathrm{M}$ cyclothiazide (CTZ) in addition to the agonist glutamate. Cyclothiazide is known to virtually completely block desensitization of flip variants of AMPA receptors (Partin et al., 1993, 1994). We detected that the potency of cyclothiazide to increase glutamate-induced currents of GluR1(Q)flip is reduced when a TARP is coexpressed, and this influence was specific for each TARP (Fig. 6A,B). This finding was surprising because Tomita et al. (2006) observed no $\gamma 2$ induced alteration of the potency of CTZ for the flip-spliced variant of GluR1. In our hands, CTZ potentiated glutamate-induced currents $57 \pm 15$-fold $(n=5)$ when GluR1(Q)flip was expressed without any TARP. Coexpression with $\gamma 8$ reduced this potentiation by CTZ to $32 \pm 7$-fold $(n=5)$, which was the weakest impact of TARPs on the potency of CTZ (Fig. $6 B$ ). Coexpression of $\gamma 4$ resulted in the largest reduction of potency of CTZ, reducing the potentiation factor to $7.1 \pm 0.6$-fold $(n=7) . \gamma 2$ and $\gamma 3$ had intermediate and comparable effects on the potency of CTZ (19 \pm 2 -fold for $\gamma 2$ and $\gamma 3$; both $n=7$ ). It should be noted that CTZ potentiated glutamate-induced responses to the same absolute amplitudes regardless of the coexpressed TARP, which themselves caused different basal current levels in the absence of CTZ. Additionally, coapplication of cyclothiazide and glutamate resulted in smaller $I_{\mathrm{KA}} / I_{\mathrm{Glu}+\mathrm{CTZ}}$ ratios for GluR1(Q)flip and also for each coexpression with a TARP compared with the respective $I_{\mathrm{KA}} / I_{\mathrm{Glu}}$ ratios (Fig. $6 C$ ). The largest reduction was seen for the $I_{\mathrm{KA}} / I_{\mathrm{Glu}}$ ratio determined for the combination of GluR1(Q)flip and $\gamma 2$, which was 

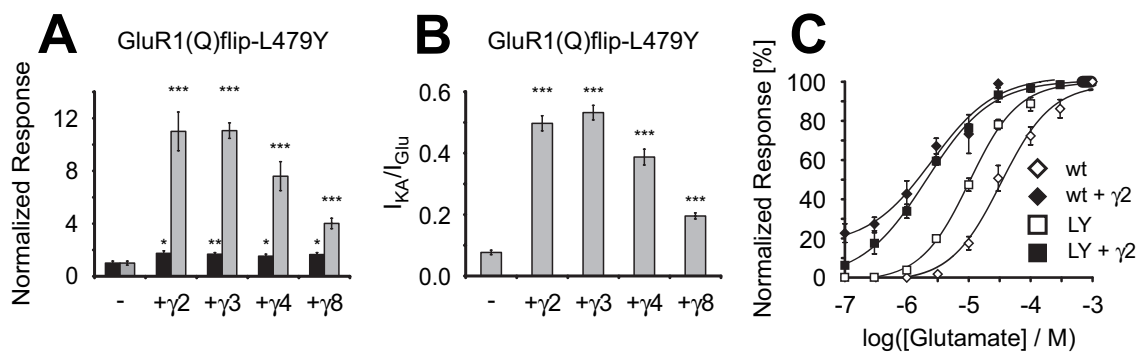

Figure 5. Influence of TARPs on the desensitization properties of AMPA receptors. A, Xenopus laevis oocytes injected with $2 \mathrm{ng}$ of GluR1(Q)flip-L479Y CRNA, and $0.2 \mathrm{ng}$ of TARP CRNA were recorded in magnesium Ringer's solution $4-5 \mathrm{~d}$ after injection. Glutamate-induced (black columns) and kainate-induced (gray columns) responses of GluR1(Q)flip-L479Y alone and in combination with each of the four TARPs were recorded. To quantify the increase in agonist-induced currents, agonist-induced currents without coexpression of a TARP were set to 1 for GluR1(Q)flip-L479Y (mean absolute current responses, $4270 \pm 644 \mathrm{nA}$ for glutamate and $341 \pm 53 \mathrm{nA}$ for kainate). Data are shown \pm SEM $(n=5-7)$. $\boldsymbol{B}$, Ratios of kainate- to glutamate-induced currents were calculated for five to seven oocytes and averaged. Data are shown \pm SEM. C, Dose-response curves for the agonist L-glutamate were determined from oocytes expressing GluR1(Q)flip or GluR1(Q)flip-L479Y in the presence or absence of $\gamma 2$. Values are means \pm SEM $(n=4-6)$, normalized to the maximal responses. The $\mathrm{EC}_{50}$ values are given in Results.

more, agonist-induced currents of AMPA receptors of the flop isoform are more strongly increased than currents of the flip isoform (except for GluR3). Additionally, we observed a stronger enlargement of agonist-induced currents by TARPs for the edited $\mathrm{R}$ isoform compared with the unedited Q isoform. Heteromeric AMPA receptor combinations were found to be modulated by TARPs in an individual manner, because the impact of TARPs on heteromeric receptors does not reflect their impact on the contributing individual homomeric subunits. Coexpression of TARPs with AMPA receptors shifted the ratio of kainate- to glutamate-induced currents to higher values but to different extents depending on both the coexpressed AMPA receptor and TARP. The shift of

A GluR1(Q)flip
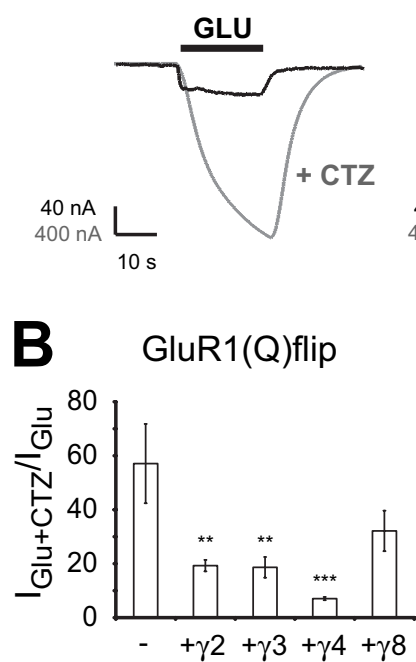

C

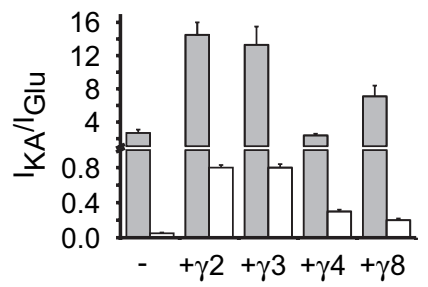

Figure 6. The impact of cyclothiazide on GluR1(Q)flip depends on the associated TARP. $A, B$ Glutamate-induced responses of AMPA receptors alone and in combination with each of the four TARPs were recorded in Xenopus laevis oocytes in the presence or absence of $100 \mu \mathrm{m} \mathrm{CTZ.}$ For GluR1(Q)flip and GluR1(Q)flip $+\gamma 2$, responses are illustrated in the presence (gray trace; bottom scale on the $y$-coordinate) and in the absence (black trace; top scale on the $y$-coordinate) of CTZ $(\boldsymbol{A}) . I_{\mathrm{Glu}+\mathrm{CTZ}} / I_{\mathrm{Glu}}$ ratios were calculated for each oocyte and averaged [ $\pm \mathrm{SEM}$; ${ }^{* *} p<$ $0.01{ }^{* * *} p<0.005$ compared with GluR1(Q)flip; $\boldsymbol{B}$ ]. C, Ratios of kainate-to glutamate-induced currents were calculated for five to eight oocytes and averaged. Gray columns indicate $I_{\mathrm{KA}} / I_{\mathrm{Glu}}$ ratios, and white columns show $I_{\mathrm{KA}} / I_{\mathrm{Glu}}$ ratios determined with $300 \mu \mathrm{m}$ glutamate in the presence of $100 \mu \mathrm{M}$ CTZ. Data are shown \pm SEM. Note the different scales on the $y$-axis and the break in $y$-axis and columns.

reduced from $14.5 \pm 1.4$ to $0.8 \pm 0.0$ in presence of cyclothiazide (both $n=7$ ), whereas the smallest reduction was seen for the combination with $\gamma 4$ because the $I_{\mathrm{KA}} / I_{\mathrm{Glu}}$ ratio was reduced from $2.4 \pm$ 0.2 to $0.3 \pm 0.0$ (both $n=7$ ) (Fig. $6 C$ ). The ranking and values of the $I_{\mathrm{KA}} / I_{\mathrm{Glu}+\mathrm{CTZ}}$ ratios are nearly identical to the values of the $I_{\mathrm{KA}} / I_{\mathrm{Glu}}$ ratio determined for the GluR1(Q)flip-L479Y mutant in coexpression with each of the four TARPs, which indicates that both the introduction of the LY mutation and the application of CTZ have equal impacts on the interaction of TARPs with AMPA receptors.

In summary, our data imply that the modulation of electrophysiological properties of AMPA receptors critically depends on both the coexpressed receptor subunit and the TARP. Further- the $I_{\mathrm{KA}} / I_{\mathrm{Glu}}$ ratio was strongest in the case of coexpression with $\gamma 2$ or $\gamma 3$ and weakest for coexpression with $\gamma 4$. $\gamma 8$ had an intermediate effect on this ratio. We demonstrated that the ability to shift the $I_{\mathrm{KA}} / I_{\mathrm{Glu}}$ ratio correlates mainly with the degree of inhibition of AMPA receptor desensitization by coexpressed TARPs and to a much lesser extent with the increase of the effectiveness of the partial agonist kainate. Also, we found a pronounced decrease in the $\mathrm{EC}_{50}$ for the physiological agonist glutamate, the degree of which was dependent on the coexpressed TARP.

\section{Discussion}

We establish that each of the four members of the TARP family is capable of potentiating agonist-induced responses at all four AMPA receptors, flip as well as flop splice variants, and Q as well as $\mathrm{R}$ editing versions. We show that TARP-mediated increase of cell surface receptor expression in Xenopus oocytes does not cause the observed large increase in currents, implying that most of the increase results from TARP-specific modulation of electrophysiological receptor properties. The extent of that modulation primarily depends on the individual receptor/TARP combination. For most homomerically expressed AMPA receptor subunits, $\gamma 2, \gamma 3$, and $\gamma 4$ were the most effective TARPs in increasing glutamate-induced currents. For kainate-induced currents, $\gamma 2$ and $\gamma 3$ were most effective, whereas $\gamma 8$ had the weakest effect with both agonists. Thus, TARP efficiencies are essentially independent of the associated AMPA receptor subunits and reflect mainly TARP properties. AMPA receptors and TARPs share a restricted regional and developmental distribution pattern throughout the CNS (Tomita et al., 2003; Beneyto and Meador-Woodruff, 2004). However, observed electrophysiological properties of distinct AMPA receptor/TARP combinations could not be correlated with a known codistribution pattern of AMPA receptors and TARPs. AMPA receptors underlie developmental modifications such as $\mathrm{Q} / \mathrm{R}$ editing and alternative splicing. During embryogenesis, low levels of unedited GluR2 can be detected, and GluR1 is mostly spliced to the flip variant (Burnashev et al., 1992; Nutt and Kamboj, 1994; Jakowec et al., 1995). However, we could not detect any striking differences in the modulation of these receptor variants in coexpression with $\gamma 4$, the predominant TARP in this developmental period (Tomita et al., 2003), compared with the modulation of subunits predominantly expressed in the adult. 


\section{The flip/flop domain: a structural determinant for TARP efficacy}

Each given TARP led to distinct current potentiation factors, varying with the receptor subunits (Fig. 2). For kainate, and more strongly glutamate, currents of flop-spliced receptor variants were increased more than those of the corresponding flip variants. This observation extends previous reports for $\gamma 2$ (Priel et al., 2005; Tomita et al., 2005) and $\gamma 3$ (Turetsky et al., 2005) that these two TARPs decrease AMPA receptor desensitization. Our data imply that all TARPs decrease receptor desensitization and show a generally larger impact on the faster desensitizing (Mosbacher et al., 1994) flop-spliced receptors, with the notable exception of GluR3. Although GluR3(Q)flop desensitizes fivefold faster than GluR1(Q)flop, this cannot explain the unique behavior of GluR3(Q)flop because GluR4(Q)flop possesses comparable desensitization properties (Mosbacher et al., 1994). R/G editing (Lomeli et al., 1994) can also be ruled out because both variants of GluR2 contain the same amino acid (glycine) at this position as GluR3. Differences between GluR3 and other AMPA receptors have been reported for the flop-specific desensitization inhibitor PEPA (2,6-difluoro-4-[2-(phenylsulfonylamino)ethylthio]-phenoxyacetamide) (Sekiguchi et al., 2002). Because interacting molecules can distinguish between AMPA receptors, TARPs could potentially exploit those same molecular differences. These findings emphasize the importance of specific AMPA receptor subunits for TARP-mediated modulation.

\section{Q/R site amino acid and subunit composition of heteromeric receptors influence TARP-dependent modulation}

Because the edited GluR2(R)flip is potentiated much stronger than the unedited GluR2(Q)flip, this may suggest that TARPs lead to an inherently more pronounced modification of electrophysiological properties of R-edited versus unedited (Q) subunits, possibly a result of more efficient protein-protein interactions.

Our analysis of heteromeric AMPA receptors revealed that TARP effects on heteromers cannot be predicted from effects on homomers. In particular, TARP effects on heteromeric receptors are neither the sum nor the mean of their effects on homomeric receptors but differ individually. This dramatically increases the complexity of receptor modulation by TARPs and AMPA receptor functional diversity.

\section{New insights into the interplay between TARPs and the modulatory effects of CTZ and the L479Y mutation}

We demonstrated that the L479Y mutation in GluR1(Q) does not alter effects of $\gamma 2$ on glutamate-induced currents, a finding contradicting Tomita et al. (2007). For this virtually nondesensitizing mutant, we determined an approximately twofold potentiation of glutamate-induced currents by $\gamma 2$. This potentiation is fully explained by increased surface receptor expression and possibly a small inhibition of residual receptor desensitization.

We further demonstrated a TARP-dependent, variable decrease in the potency of the desensitization inhibitor CTZ. These findings contradict previous reports that $\gamma 2$ does not decrease the potency of CTZ for GluR1flip (Tomita et al., 2006). The decrease observed here could be attributable to a TARP dependency of CTZ efficacy or to a TARP-dependent decrease in receptor desensitization, because a strong inhibition of receptor desensitization would result in a reduced apparent potency of CTZ. We favor the second explanation but cannot rule out the first or a combination of both.
TARP-induced reduction of receptor desensitization depends on TARPs as well as on AMPA receptors

TARP-mediated modulation of electrophysiological properties has been attributed to two distinct mechanisms: reduction of desensitization and increase in apparent kainate efficacy (Tomita et al., 2005; Turetsky et al., 2005). Both mechanisms influence the ratio of kainate- to glutamate-induced currents. This ratio increases when the relative kainate efficacy increases but decreases when receptor desensitization is reduced, which enlarges glutamate-induced currents. We observed a distinctly TARPspecific increase in $I_{\mathrm{KA}} / I_{\mathrm{Glu}}$ ratios, implying that the increase in apparent kainate efficacy outweighs any TARP-mediated reduction in receptor desensitization (Table 1 ). We tested whether high $I_{\mathrm{KA}} / I_{\mathrm{Glu}}$ ratios were correlated with strong TARP-dependent increases in kainate-induced currents. For $\gamma 2$ and $\gamma 3$, this correlation mostly held up but not for $\gamma 4$ and $\gamma 8$ (Fig. 2, Table 1). Despite causing the smallest increase in kainate-induced responses for most AMPA receptors, $\gamma 8$ robustly increased $I_{\mathrm{KA}} / I_{\mathrm{Glu}}$ ratios. Thus, there is no correlation between a high $I_{\mathrm{KA}} / I_{\mathrm{Glu}}$ ratio and the TARP-dependent increase in kainate-induced currents. The second possible factor, a TARP-dependent decrease in receptor desensitization, was investigated by expressing the virtually nondesensitizing GluR1(Q)flip-L479Y mutant with each of the four TARPs (Fig. 5A). Additionally, we coapplied the desensitization inhibitor cyclothiazide plus glutamate to all four GluR1(Q)flip/TARP combinations (Fig. 6). Both approaches yielded identical results, because glutamate-induced currents were increased to the same level independently of the TARP. The increase in kainate-induced currents, however, showed a distinct dependency on the coexpressed TARP (Fig. 5A).

We conclude that each TARP decreases wild-type receptor desensitization to a different extent, thus explaining the observed diverse TARP-mediated increases in $I_{\mathrm{KA}} / I_{\mathrm{Glu}}$ ratios. For example, $\gamma 4$ in coexpression with almost all AMPA receptors led to the smallest increase in the $I_{\mathrm{KA}} / I_{\mathrm{Glu}}$ ratios of all TARPs (Table 1 ). However, $\gamma 4$ does not cause the weakest increase in kainate efficacy among TARPs (Fig. 5A); a weak increase in kainate efficacy can be ruled out as an explanation. The small increases in wildtype $I_{\mathrm{KA}} / I_{\mathrm{Glu}}$ ratios therefore imply a counteracting strong decrease in receptor desensitization. This may constitute a functional correlation with the peculiar expression of $\gamma 4$ during development that differs from all other TARPs (Tomita et al., 2003). Our findings also suggest that TARP-mediated modulation of AMPA receptors is strongly dependent on the applied agonist. It might be speculated that the agonist-dependent modulation of AMPA receptors is based on multiple interaction sites between AMPA receptors and TARPs, which contribute differentially in any given AMPA receptor/TARP combination. Additionally, it is possible that, in certain combinations, not all potential interaction sites contribute to the subunit interface.

The largest TARP-mediated increases in $I_{\mathrm{KA}} / I_{\mathrm{Glu}}$ ratios were seen for the fast-desensitizing receptor subunits GluR3(Q)flop and GluR4(Q)flop (Fig. 3, Table 1) because of a very weak potentiation of glutamate-induced currents coinciding with a large increase in kainate-induced currents (Fig. 2E, G). Thus, the desensitization properties of AMPA receptors may also influence the effectiveness of TARPs as ion channel modulators.

TARP modulation of agonist $\mathrm{EC}_{50}$ values suggests a mechanism for TARP/AMPA receptor interaction

We showed that all TARPs cause different reductions of the $\mathrm{EC}_{50}$ for glutamate (Fig. 1D). It had been stated that $\gamma 2$ does not decrease the low (compared with wild type) $\mathrm{EC}_{50}$ for glutamate at 
the GluR1-L479Y mutant and that therefore the $\gamma 2$-dependent decrease in the $\mathrm{EC}_{50}$ of wild-type GluR1 must be exclusively based on reduced receptor desensitization (Priel et al., 2005). To our surprise, we found a distinct additional decrease in the $\mathrm{EC}_{50}$ for glutamate of GluR1-L479Y when this mutant was coexpressed with $\gamma 2$ (Fig. $5 C$ ). We conclude that the reduction of receptor desensitization by TARPs cannot be the exclusive reason for the leftward shift in the dose-response relationships. We postulate that the association of a TARP directly or indirectly causes an efficiency-enhancing conformational change of either the ligand binding domain of the AMPA receptor or its gating domains.

This study provides additional insight into the complex modulation of electrophysiological properties of AMPA receptors, particularly desensitization and ligand efficacies, by TARPs. The degree of modulation is crucially dependent on both interaction partners and especially on key structural properties of the receptor subunit such as the flip/flop domain and the amino acid located at the Q/R editing site. Importantly, heteromeric AMPA receptor complexes are TARP-specifically modulated according to their subunit and also splice variant composition. This illuminates the importance of TARPs for the complexity of AMPA receptor-mediated synaptic transmission in the CNS.

\section{References}

Beneyto M, Meador-Woodruff JH (2004) Expression of transcripts encoding AMPA receptor subunits and associated postsynaptic proteins in the macaque brain. J Comp Neurol 468:530-554.

Brorson JR, Li D, Suzuki T (2004) Selective expression of heteromeric AMPA receptors driven by flip-flop differences. J Neurosci 24:3461-3470.

Burnashev N, Monyer H, Seeburg PH, Sakmann B (1992) Divalent ion permeability of AMPA receptor channels is dominated by the edited form of a single subunit. Neuron 8:189-198.

Chen C, Okayama H (1987) High-efficiency transformation of mammalian cells by plasmid DNA. Mol Cell Biol 7:2745-2752.

Chen L, Chetkovich DM, Petralia RS, Sweeney NT, Kawasaki Y, Wenthold RJ, Bredt DS, Nicoll RA (2000) Stargazin regulates synaptic targeting of AMPA receptors by two distinct mechanisms. Nature 408:936-943.

Chu PJ, Robertson HM, Best PM (2001) Calcium channel gamma subunits provide insights into the evolution of this gene family. Gene 280:37-48.

Cognet L, Groc L, Lounis B, Choquet D (2006) Multiple routes for glutamate receptor trafficking: surface diffusion and membrane traffic cooperate to bring receptors to synapses. Sci STKE 327:pe13.

Collingridge GL, Isaac JT, Wang YT (2004) Receptor trafficking and synaptic plasticity. Nat Rev Neurosci 5:952-962.

Greger IH, Khatri L, Ziff EB (2002) RNA editing at arg607 controls AMPA receptor exit from the endoplasmic reticulum. Neuron 34:759-772.

Greger IH, Khatri L, Kong X, Ziff EB (2003) AMPA receptor tetramerization is mediated by Q/R editing. Neuron 40:763-774.

Hollmann M (1999) Structure of ionotropic glutamate receptors. In: Handbook of experimental pharmacology, Vol 141, Ionotropic glutamate receptors in the CNS (Jonas P, Monyer H, ed), pp 3-98. Berlin: Springer.

Hollmann M, Heinemann S (1994) Cloned glutamate receptors. Annu Rev Neurosci 17:31-108.

Hollmann M, Hartley M, Heinemann S (1991) Calcium permeability of KA-AMPA gated glutamate receptor channels depends on subunit composition. Science 252:851-853.

Hume RI, Dingledine R, Heinemann S (1991) Identification of a site in glutamate receptor subunits that controls calcium permeability. Science 253:1028-1031.

Jakowec MW, Yen L, Kalb RG (1995) In situ hybridization analysis of AMPA receptor subunit gene expression in the developing rat spinal cord. Neuroscience 67:909-920.

Lomeli H, Mosbacher J, Melcher T, Hoger T, Geiger JR, Kuner T, Monyer H, Higuchi M, Bach A, Seeburg PH (1994) Control of kinetic properties of AMPA receptor channels by nuclear RNA editing. Science 266:1709-1713.

Mansour M, Nagarajan N, Nehring RB, Clements JD, Rosenmund C (2001)
Heteromeric AMPA receptors assemble with a preferred subunit stoichiometry and spatial arrangement. Neuron 32:841-853.

Mosbacher J, Schoepfer R, Monyer H, Burnashev N, Seeburg PH, Ruppersberg JP (1994) A molecular determinant for submillisecond desensitization in glutamate receptors. Science 266:1059-1062.

Nakagawa T, Cheng Y, Ramm E, Sheng M, Walz T (2005) Structure and different conformational states of native AMPA receptor complexes. Nature 433:545-549.

Nicoll RA, Tomita S, Bredt DS (2006) Auxiliary subunits assist AMPA-type glutamate receptors. Science 311:1253-1256.

Nutt SL, Kamboj RK (1994) Differential RNA editing efficiency of AMPA receptor subunit GluR2 in human brain. NeuroReport 5:1679-1683.

Partin KM, Patneau DK, Winters CA, Mayer ML, Buonanno A (1993) Selective modulation of desensitization at AMPA versus kainate receptors by cyclothiazide and concanavalin A. Neuron 11:1069-1082.

Partin KM, Patneau DK, Mayer ML (1994) Cyclothiazide differentially modulates desensitization of $\alpha$-amino-3-hydroxy-5-methyl-4-isoxazolepropionic acid receptor splice variants. Mol Pharmacol 46:129-138.

Priel A, Kolleker A, Ayalon G, Gillor M, Osten P, Stern-Bach Y (2005) Stargazin reduces desensitization and slows deactivation of the AMPA-type glutamate receptors. J Neurosci 25:2682-2686.

Rosenmund C, Stern-Bach Y, Stevens CF (1998) The tetrameric structure of a glutamate-receptor channel. Science 280:1596-1599.

Sekiguchi M, Nishikawa K, Aoki S, Wada K (2002) A desensitizationselective potentiator of AMPA-type glutamate receptors. Br J Pharmacol 136:1033-1041.

Sheng M, Lee SH (2003) AMPA receptor trafficking and synaptic plasticity: major unanswered questions. Neurosci Res 46:127-134.

Sommer B, Keinänen K, Verdoorn TA, Wisden W, Burnashev N, Herb A, Köhler M, Takagi T, Sakmann B, Seeburg PH (1990) Flip and flop: a cell-specific functional switch in glutamate-operated channels of the CNS. Science 249:1580-1585.

Stern-Bach Y, Russo S, Neuman M, Rosenmund C (1998) A point mutation in the glutamate binding site blocks desensitization of AMPA receptors. Neuron 21:907-918.

Sun Y, Olson R, Horning M, Armstrong N, Mayer M, Gouaux E (2002) Mechanism of glutamate receptor desensitization. Nature 417:245-253.

Swanson GT, Kamboj SK, Cull-Candy SG (1997) Single channel properties of recombinant AMPA receptors depend on RNA editing, splice variation, and subunit composition. J Neurosci 17:58-69.

Tomita S, Chen L, Kawasaki Y, Petralia RS, Wenthold RJ, Nicoll RA, Bredt DS (2003) Functional studies and distribution define a family of transmembrane AMPA receptor regulatory proteins. J Cell Biol 161:805-816.

Tomita S, Adesnik H, Sekiguchi M, Zhang W, Wada K, Howe JR, Nicoll RA, Bredt DS (2005) Stargazin modulates AMPA receptor gating and trafficking by distinct domains. Nature 435:1052-1058.

Tomita S, Sekiguchi M, Wada K, Nicoll RA, Bredt DS (2006) Stargazin controls the pharmacology of AMPA receptor potentiators. Proc Natl Acad Sci USA 103:10064-10067.

Tomita S, Shenoy A, Fukata Y, Nicoll RA, Bredt DS (2007) Stargazin interacts functionally with the AMPA receptor glutamate-binding module. Neuropharmacology 52:87-91.

Turetsky D, Garringer E, Patneau DK (2005) Stargazin modulates native AMPA receptor functional properties by two distinct mechanisms. J Neurosci 25:7438-7448.

Vandenberghe W, Nicoll RA, Bredt DS (2005) Stargazin is an AMPA receptor auxiliary subunit. Proc Natl Acad Sci USA 102:485-490.

Villmann C, Bull L, Hollmann M (1997) Kainate binding proteins possess functional ion channel domains. J Neurosci 17:7634-7643.

Villmann C, Strutz N, Morth T, Hollmann M (1999) Investigation by ion channel domain transplantation of rat glutamate receptor subunits, orphan receptors and a putative NMDA receptor subunit. Eur. J Neurosci 11:1765-1778.

Wenthold RJ, Petralia RS, Blahos J, Niedzielski AS (1996) Evidence for multiple AMPA receptor complexes in hippocampal CA1/CA2 neurons. J Neurosci 16:1982-1989.

Yamazaki M, Ohno-Shosaku T, Fukaya M, Kano M, Watanabe M, Sakimura K (2004) A novel action of stargazin as an enhancer of AMPA receptor activity. Neurosci Res 50:369-374. 